\title{
The study on mechanical properties of HDPE reinforced carbon fiber powder composites for acetabular cup
}

\author{
Devaraj.E ${ }^{1}$, Chandrashekhar Bendigeri² \\ ${ }^{1}$ Research scholar, UVCE and Asst. Professor, Department of Mechanical Engg, CMRU, Bangalore, \\ Karnataka, India \\ ${ }^{2}$ Professor, Department of Mechanical Engg, UVCE, Bangalore, Karnataka, India
}

\begin{abstract}
Metallic implants have been used widely in a lot of orthopaedic applications. Titanium, Ceramics, medical grade titanium and other metal alloys are been used a lot in orthopaedic implants. The disadvantages of metal implants however are corrosion and the release of ions, so there is need for finding new acetabular cup materials like polymer composites. This work is part of the manufacturing and processing of carbon fibre powder/HDPE composite and the study of its mechanical properties. Mechanical properties are estimated by ASTM standard methods. Results are represented according to evaluation of composite performance mechanically and show the best choice of composite parts in order to improve future use in acetabular cups.
\end{abstract}

Keywords: HDPE Polymer, Injection moulding process, Orthopaedic implants, Mechanical Properties.

\section{INTRODUCTION}

Lately, the interest in composite materials is expanding because of their benefits when contrasted with solid metal combinations. Composites are either normally happening or designed materials that are produced using at least two constituents. At the end of the day, composites are materials that comprise of strong burden conveying building up material inserted in a more fragile grid material. Composites have two constituents. The foremost constituent of composites having a persistent stage and structures the focal piece of the composite is known as the grid (1). Framework is normally less inflexible and is more pliable. The framework can be either natural or inorganic. The optional constituent has an intermittent stage and is inserted in the grid. This is known as support (2). The constituents of composites hold their individual physical and substance properties. Notwithstanding, when consolidated, they produce a mix of properties that singular constituents would be unequipped for delivering alone. In the previous decade, composite materials have been utilized as an option in a few lightweights. High strength is utilized as a result of their high solidarity to-weight proportion and high elasticity (3). With the consistent development and improvement in innovation, the requirement for various materials with specific properties is expanding day today. The requests can't be accomplished by utilizing existing metal composites, ceramics, and polymers (4). This is the place where composites come into the image as different metals, ceramics, and polymers can be blended to get the particular wanted properties.

The engineered fiber-built up polymer in bio-mechanical needs to start to defeat issue sort by clinical professionals. The muscular specialist is utilizing metallic plates, bone plates for human bone crack. Use of metals in bone obsession, for example, hardened steel and titanium combination, causes issues like metal incongruence, consumption, and decrease in bone mass to upgrade bone porosity (5).

Need of Composite as a Biomaterial:

Bones as hard tissue are strong and solidified and have high flexible modulus. Human bones normally are and on a very basic level composite material made of collagen fiber and nanocrystal of hydroxyapatite, silt in collagen fiber (6).

The versatile modulus of collagen fiber is low, and hydroxyapatites have a high flexible modulus which contains $70 \%$ load of the dry bone and matches the solidness of the bone. With this reality, the composite material has great biocompatibility. 


\section{International Advanced Research Journal in Science, Engineering and Technology}

Vol. 8, Issue 8, August 2021

DOI: 10.17148/IARJSET.2021.8842

\section{Objectives and Scope}

\subsection{Objectives of the Present Work}

1. Fabrication of unsaturated HDPE resin reinforced with Carbon fiber powder with and without filler additions.

2. To evaluate the Mechanical characteristics of the prepared composite materials.

a) Mechanical characteristics like tensile strength, compression, flexural strength.

b) To study effects of incorporation of with and without filler addition.

\subsection{Scope of the Present Work}

Writing close by uncovers that no single gathering of scientists has altogether portrayed the mechanical attribute of Hybrid manufactured fiber supported HDPE polymer by adding fillers material.

The current work endeavors to utilize the common reused assets to create bio-composite material for biomedical applications like bone plates, bone screws material for both inner and outside obsessions. The engineered carbon fiber power is utilized as support in the HDPE gum grid, and silicon carbide is utilized as fillers. Henceforth silicon carbide is utilized as a stabilizer to an anticipated engineered grid, the polymer connects with the earth, or water is attack through the organisms.

\subsection{Methodology}

In this experiment, the material selection is made initially:

- HDPE as the matrix

- Carbon fiber powder as reinforcement

- Silicon carbide powder as filler

These materials are mixed in different proportions, and composite material is made using the injection molding method. Tensile and flexural tests of composite materials are done in Tensometer.

\subsection{Selection of Matrix Phase}

\section{Selection of Materials}

HDPE has been selected as a matrix as it is a polyethylene thermoplastic made from petroleum with a high strength-to-density ratio. The density of HDPE can range from 0.93 to $0.97 \mathrm{~g} / \mathrm{cm} 3$ or $970 \mathrm{~kg} / \mathrm{m} 3$. However, the density of HDPE is only marginally higher than that of low-density polyethylene. It is also more complicated and opaquer and can withstand somewhat higher temperatures (1200C/248 F for short periods). HDPE is non-toxic, tasteless, odorless, deficient moisture absorption, and has a very low friction coefficient and hence wear resistance. HDPE is among the most widely used polyolefin because of its high strength, meager cost, excellent process ability, and high chemical resistance.

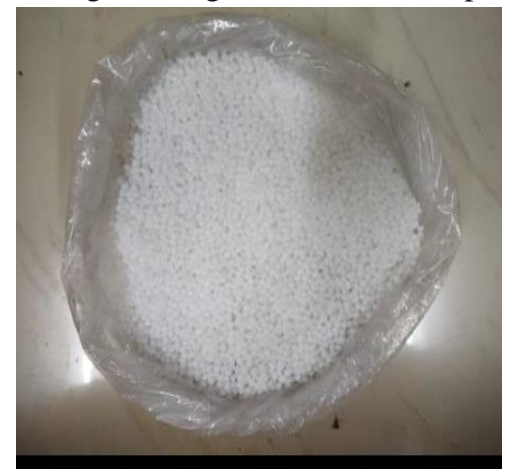

Fig 1: HDPE

\subsection{Selection of Carbon fiber Powder}

The reinforcement in a composite material fundamentally increases the mechanical properties and provides strength to the finished part. The most commonly used reinforcement materials are carbon fiber powder. This is because many of the desired performance characteristics require the use of carbon/graphite fibers. Fibers are about 5-10 micrometers in diameter and composed mainly of carbon atoms. Carbon fibers have several advantages, including high 


\section{International Advanced Research Journal in Science, Engineering and Technology}

Vol. 8, Issue 8, August 2021

DOI: $10.17148 /$ IARJSET.2021.8842

stiffness, high tensile strength, low weight, high chemical resistance, high-temperature tolerance, and low thermal expansion.

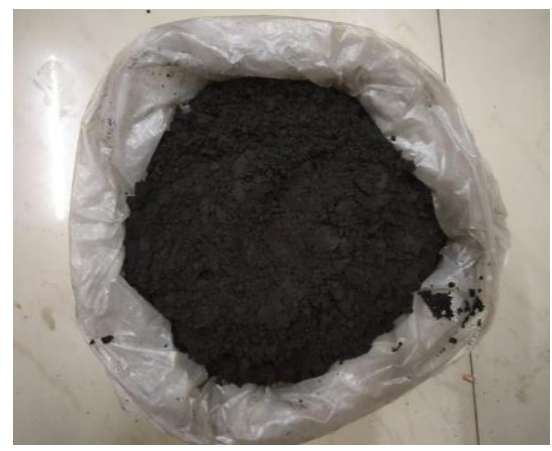

Fig 2: Carbon fiber powder

\subsection{Selection of silicon carbide filler}

Fillers are particles added to material (plastics, composite material, and concrete) to lower the consumption of more expensive binder material or better some mixture material properties. Silicon carbide is an excellent abrasive. It has high strength, low thermal expansion, high thermal conductivity, high hardness, high elastic modulus, excellent thermal shock resistance, superior chemical inertness.

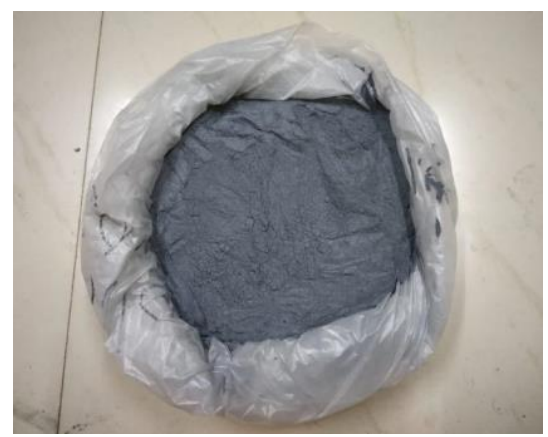

Fig 3: silicon carbide powder

\subsection{New data collected}

The polymer composites samples are prepared with following compositions:

Table 1: Constituents and their concentration in the prepared composites

\begin{tabular}{|c|c|c|c|c|c|c|}
\hline S.. No & \multirow{2}{*}{ Composition } & Composites & Reinforcement (\%) & Matrix (\%) & \multicolumn{2}{|c|}{ Filler (\%) } \\
\cline { 4 - 7 } & & SiC & $\mathbf{A l}_{2} \mathbf{O}_{3}$ \\
\hline 1 & HSB1 & $\begin{array}{c}\text { Carbon fibre } \\
\text { powder/HDPE }\end{array}$ & 0 & 100 & 0 & 0 \\
\hline 2 & HSB2 & $\begin{array}{c}\text { Carbon fibre } \\
\text { powder/HDPE }\end{array}$ & 30 & 70 & 0 & 0 \\
\hline 3 & HSB3 & $\begin{array}{c}\text { Carbon fibre } \\
\text { powder/HDPE }\end{array}$ & 30 & 66 & 2 & 2 \\
\hline
\end{tabular}


International Advanced Research Journal in Science, Engineering and Technology

Vol. 8, Issue 8, August 2021

DOI: $10.17148 /$ IARJSET.2021.8842

\begin{tabular}{|c|c|c|c|c|c|c|}
\hline 4 & HSB4 & $\begin{array}{c}\text { Carbon fibre } \\
\text { powder/HDPE }\end{array}$ & 30 & 62 & 4 \\
\hline 5 & HSB5 & $\begin{array}{c}\text { Carbon fibre } \\
\text { powder/HDPE }\end{array}$ & 30 & 58 & 6 & 6 \\
\hline
\end{tabular}

\section{SPECIMEN PREPARATION}

Injection molding is the most commonly used manufacturing process for the fabrication of plastic parts. A wide variety of products are manufactured using injection molding, which varies significantly in their size, complexity, and application. Injection molding machines have many components and are available in different configurations, including a horizontal configuration and a vertical configuration. A vertical injection molding machine has prepared samples of different compositions.

The injection unit is responsible for both heating and injecting the material into the mold. The first part of this unit is the hopper, a large container into which the raw plastic is poured. The hopper has an open bottom, which allows the material to feed into the barrel. The barrel contains the mechanism for heating and injecting the material into the mold.

This mechanism is usually a ram injector or a reciprocating screw. A ram injector forces the material forward through a heated section with a ram or plunger that is usually hydraulically powered. In this way, composite materials are prepared in mild steel to die using vertical injection molding. These specimens are then cut by water jet machining, using ASTM standard for tensile and flexural test. The size of the die used is $120 \mathrm{~mm} * 120 \mathrm{~mm} * 3 \mathrm{~mm}$.

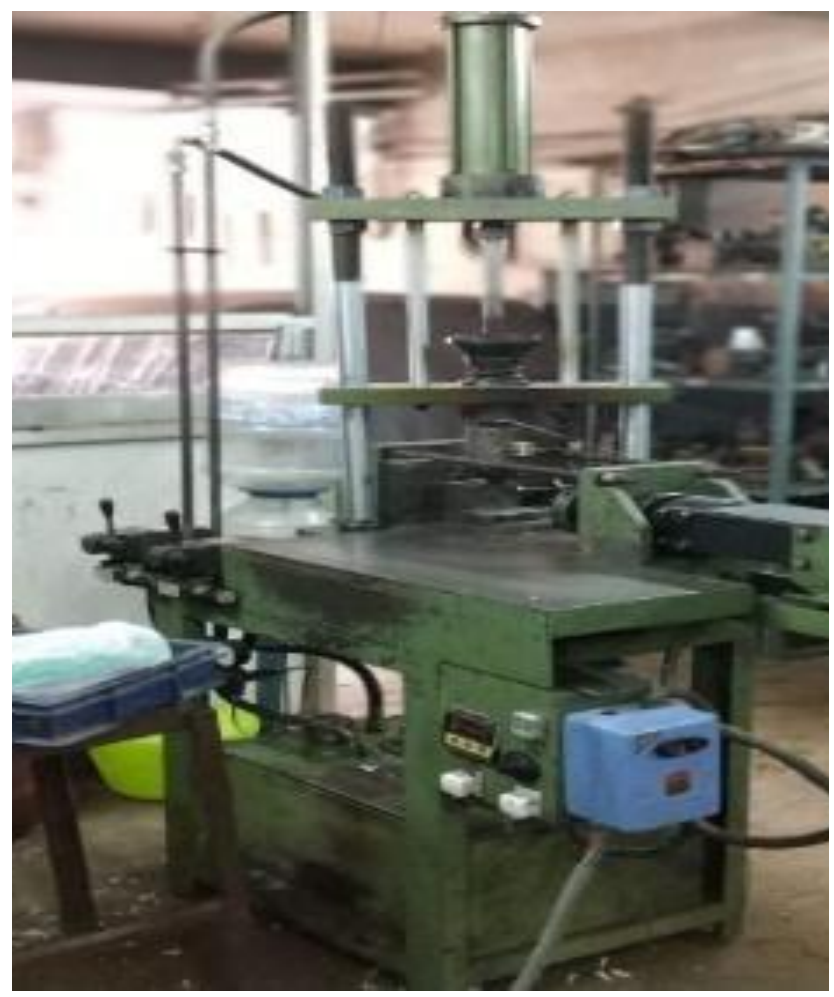

Fig 4: Injection molding machine 


\section{International Advanced Research Journal in Science, Engineering and Technology}

Vol. 8, Issue 8, August 2021

DOI: $10.17148 /$ IARJSET.2021.8842
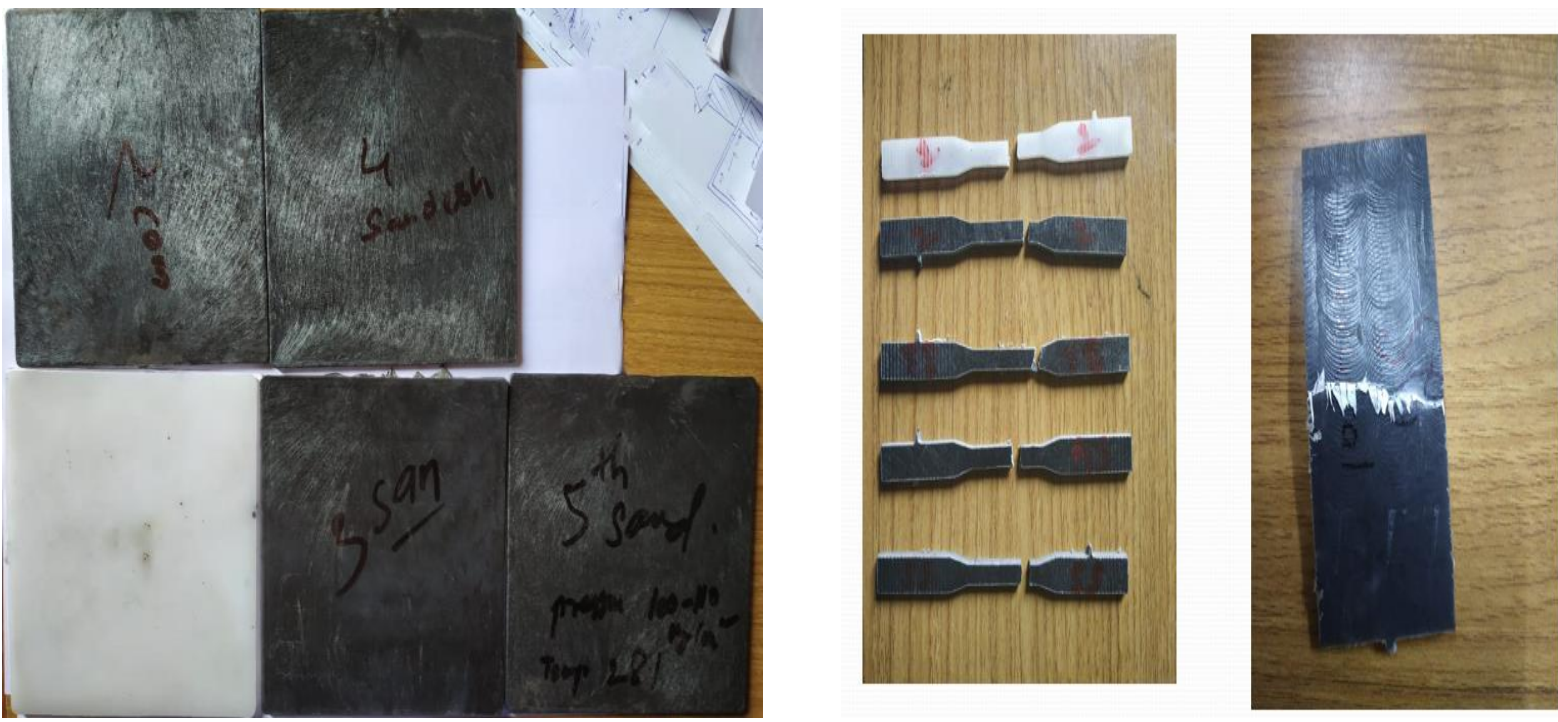

Fig 5: Final product is prepared

Fig 6: Specimen for testing according to ASTM STD

\section{RESULTS AND DISCUSSION}

\subsection{Tensile Test}

\section{Tensile Peak load: According to ASTM-E8}

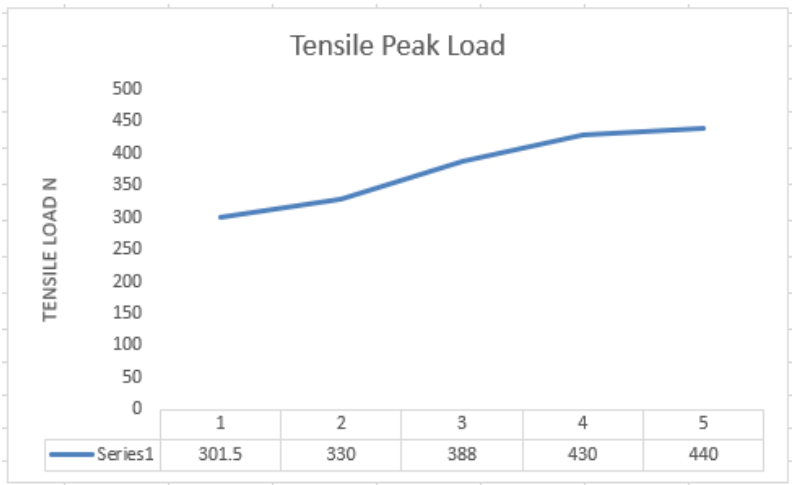

Fig 7: Peak load Figure

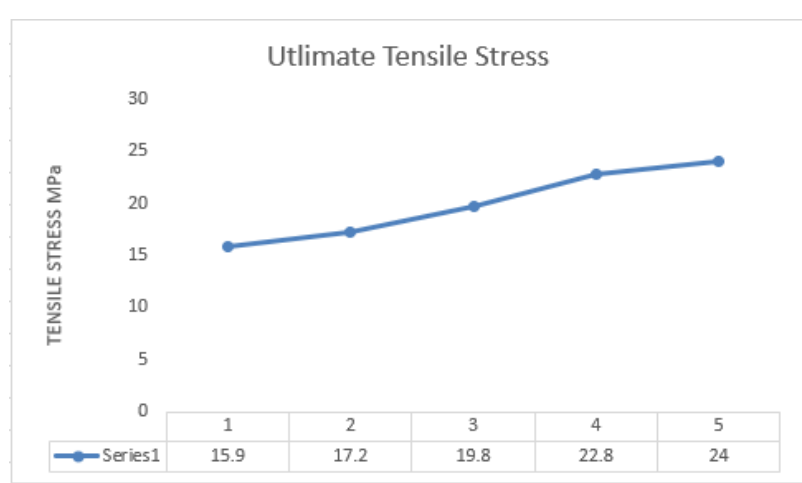

Fig 8: Ultimate tensile stress

The results of peak load and ultimate strength as a function of filler content of neat HDPE and their composites are shown in figure 7. For all the composites tested, it is observed that the strength increases linearly with an increase in filler contents.

At $6 \% \mathrm{SiC}$ and $6 \% \mathrm{Al}_{2} \mathrm{O}_{3}$ filler content with $30 \%$ carbon fiber powder reinforced $58 \% \mathrm{HDPE}$ has the Peak Load of 440 $\mathrm{N}$, ultimate stress of 24.0 MPa, and the lowest value of $301.5 \mathrm{~N}$, ultimate strength of 15.9 MPa for Pure HDPE polymer.

The ultimate tensile strength is an engineering value calculated by dividing the maximum load on a material by the test specimen's initial cross-section. Figure 8 shows the tensile strength graph versus the Aluminum oxide filler and silicon carbide filler filled with the carbon fiber powder-reinforced HDPE composite. Tensile strength increases from 0 to $6 \mathrm{wt}$. \% Aluminum oxide filler and silicon carbide filler content is shown in figure 8 , whereas the further increase in Aluminum oxide and silicon carbide filler content increases in tensile strength value. This is because filler particles act as a barrier in transferring stress from one point to another and increasing aluminum oxide and silicon carbide added content up to $6 \mathrm{wt}$. \% results in the increase of transfer of stresses from one point to another. Also, as the fiber/filler content increases, the bonding surface area increases, and hence bonding strength increases. Due to the sufficient amount 


\section{International Advanced Research Journal in Science, Engineering and Technology}

Vol. 8, Issue 8, August 2021

DOI: $10.17148 /$ IARJSET.2021.8842

of bonding between three different constituents, the loads are effectively transferred from one end to another. Hence, there is increase in the tensile strength of the polymer composite.

\subsection{Compression Test}

\section{Compression Peak load: According to ASTM D-695}

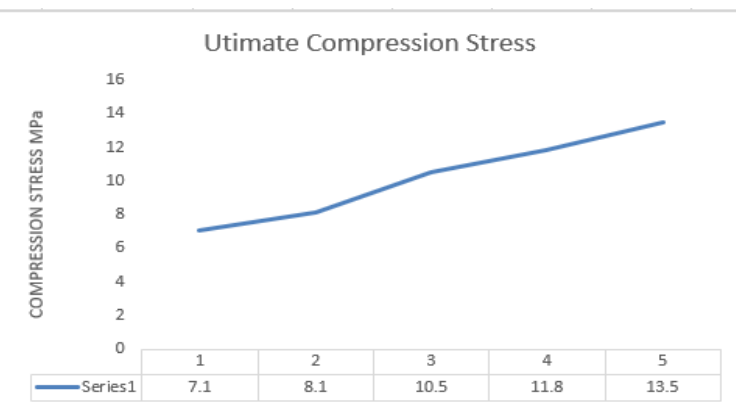

Fig 9: Compression Peak load

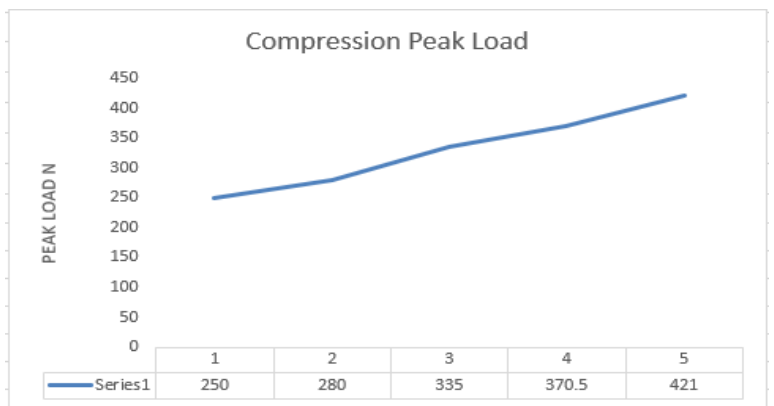

Fig 10: Ultimate compression stress

\section{Ultimate compression stress}

The results of peak load and ultimate compressive stress as a function of filler content of neat HDPE and their composites are shown in figure 9 . For all the composites tested, it is observed that the strength increases linearly with an increase in filler content.

At $6 \% \mathrm{SiC}$ and $6 \% \mathrm{Al}_{2} \mathrm{O}_{3}$ filler content with $30 \%$ carbon fiber powder reinforced $58 \% \mathrm{HDPE}$ has the Peak Load of $421 \mathrm{~N}$, ultimate stress of 13.5 MPa, and the lowest value of 250N, ultimate strength of 7.1 MPa for Pure HDPE polymer.

This is because $\mathrm{SiC}-\mathrm{Al}_{2} \mathrm{O}_{3}$ filler content with Carbon fiber powder reinforced HDPE composite, HDPE reinforced carbon filler powder with filler addition content shows better results than the pure HDPE.

\subsection{Bending Test}

Bending Peak load: According to ASTM D-790

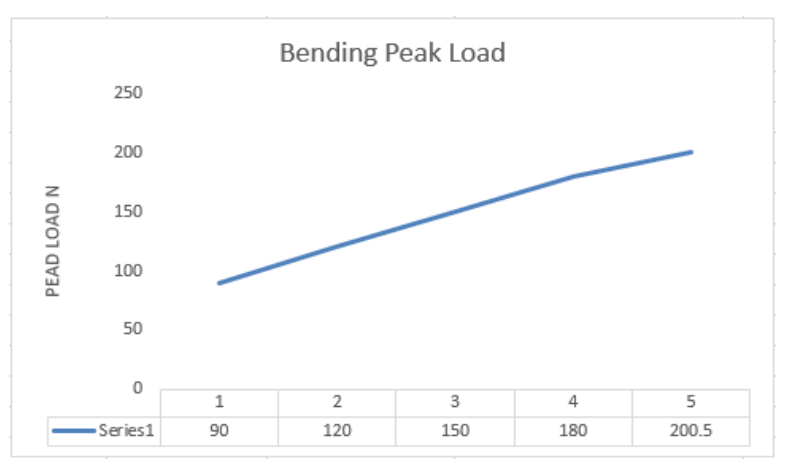

Fig 11: Bending Peak load

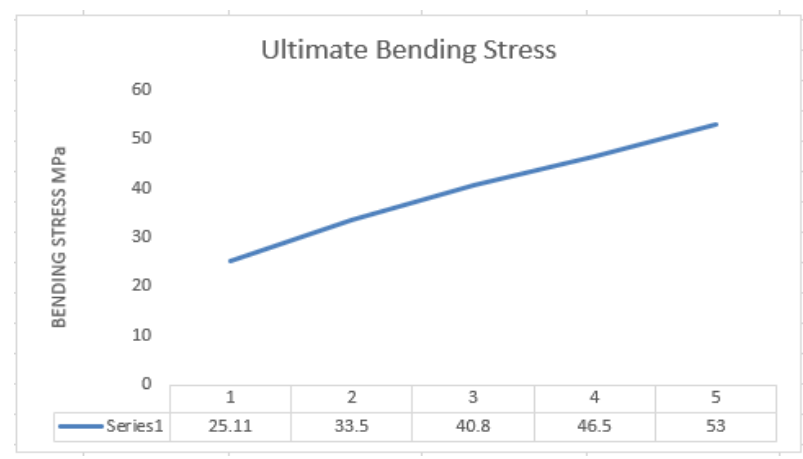

Figure 12: Ultimate bending stress

\section{Ultimate bending stress}

The results of peak load and ultimate strength as a function of filler content of neat HDPE and their composites are shown in figure 11. For all the composites tested, it is observed that the strength increases linearly with an increase in filler content.

At $6 \% \mathrm{SiC}$ and $6 \% \mathrm{Al}_{2} \mathrm{O}_{3}$ filler content with $30 \%$ carbon fiber powder reinforced $58 \%$ HDPE has the Peak Load of $200.5 \mathrm{~N}$, ultimate stress of $53 \mathrm{MPa}$, and the lowest value of 90N, ultimate strength of 25.11 MPa for Pure HDPE polymer. 


\section{International Advanced Research Journal in Science, Engineering and Technology}

Vol. 8, Issue 8, August 2021

DOI: 10.17148/IARJSET.2021.8842

This is because $\mathrm{SiC}-\mathrm{Al}_{2} \mathrm{O}_{3}$ filler content with Carbon fiber powder reinforced HDPE composite, HDPE reinforced carbon filler powder with filler addition content shows better results than the pure HDPE.

\section{CONCLUSION}

The current work has been undertaken, to explore the potential of the treated carbon fiber powder reinforced HDPE polymer composites and to learn the mechanical characteristic of the composites and therefore, mechanical properties are as follows:

Tensile Test: At $6 \% \mathrm{SiC}$ and $6 \% \mathrm{Al}_{2} \mathrm{O}_{3}$ filler content with $30 \%$ carbon fiber powder reinforced 58\% HDPE has the Peak Load of $440 \mathrm{~N}$, ultimate stress of $24.0 \mathrm{MPa}$, and the lowest value of $301.5 \mathrm{~N}$, the ultimate strength of $15.9 \mathrm{MPa}$ for Pure HDPE polymer.

Compression Test: At $6 \% \mathrm{SiC}$ and $6 \% \mathrm{Al}_{2} \mathrm{O}_{3}$ filler content with 30\% carbon fiber powder reinforced 58\% $\mathrm{HDPE}$ has the Peak Load of $421 \mathrm{~N}$, ultimate stress of $13.5 \mathrm{MPa}$ the lowest value of 250N, ultimate strength of $7.1 \mathrm{MPa}$ for Pure HDPE polymer.

Bending Test: At $6 \% \mathrm{SiC}$ and $6 \% \mathrm{Al}_{2} \mathrm{O}_{3}$ filler content with $30 \%$ carbon fiber powder reinforced 58\% $\mathrm{HDPE}$ has the Peak Load of $190.5 \mathrm{~N}$, ultimate stress of $52 \mathrm{MPa}$, and the lowest value of $90 \mathrm{~N}$, the ultimate strength of $25.11 \mathrm{MPa}$ for Pure HDPE polymer.

\section{REFERENCES}

1 Ohaga, S et al. "Mechanical and End-Use Properties of High-Density Polyethylene (HDPE) Filled with Plantain Peel Powder" SSRG International Journal of Polymer and Textile Engineering (SSRG-IJPTE) - Volume 6 Issue 3 - Sep-Dec 2019

2 Sooraj K. Pillai et al. "Development of the Property of Fly-Ash Filled HDPE Composites -Review" IOSR Journal of Polymer and Textile Engineering (IOSR-JPTE) e-ISSN: 2348-019X, p-ISSN: 2348-0181, Volume 6, Issue 3 (May. - June. 2019), P.P. 33-37

3.Sergio Augusto B Lins et al. "Mechanical and thermal properties of high-density polyethylene/alumina/glass fiber hybrid composites" Journal of Thermoplastic Composite Materials 1-16,2018.sagepub.com/journals-permissions, DOI: 10.1177/0892705718797391.

4. Sheela $\mathrm{M}$ et al. "MECHANICAL AND ELECTRICAL PROPERTIES OF BISMUTH FILLED HIGH-DENSITY POLYETHYLENE COMPOSITES" Vol-5 Issue-3 2019, IJARIIE-ISSN(O)-2395-4396.

5. Alessia Quitadamo et al." Eco-Friendly Approach and Potential Biodegradable Polymer Matrix for WPC Composite Materials in Outdoor Application" International Journal of Polymer Science, Volume 2019, Article ID 3894370, 9 pages,https://doi.org/10.1155/2019/3894370.

6. L.O. Eze et al. "Mechanical Properties of Pineapple Leaf Powder Filled High-Density Polyethylene" International Journal of Engineering and Technologies, ISSN: 2297-623X, Vol. 9, pp 13-19 doi:10.18052/www.scipress.com/IJET.9.13 Accepted: 2016-09-13 2016 SciPress Ltd, Switzerland. 7 Aini Asifa Ahmad Kamal et al. "Tensile Properties and IMPact Strength of RHDPE/BF Composites: The Effects of Chemical Treatment" IOP Conf. Series: Materials Science and Engineering 557 (2019) 012041, IOP Publishing,doi:10.1088/1757-899X/557/1/012041.

8.Sameer A. Awad et al. "An investigation of the improvements of mechanical and thermal properties of high-density polyethylene/nano clay composites ", European Mechanical Science, June 2019; 3(2): 41-44,DOI: https://doi.org/10.26701/ems.470350.

9. Aleksandra Vulović et.al "Finite Element Analysis of Femoral Implant Under Static Load", 2017 IEEE 17th International Conference on Bioinformatics and Bioengineering, 2471-7819/17/31.00 @2017 IEEE.

10. Taj et.al "Finite Element Modeling and Analysis of Hip Joint Prosthesis with Modular Stem" International Journal of Mechanical Engineering and Technology, 8(6), 2017,pp. 789-795.

11. Katarina Colica et.al " Finite element modeling of hip implant static loading" Procedia Engineering 149 ( 2016 ) 257 - 262 , doi: 10.1016/j.proeng.2016.06.664.

12. Farshid Rezaei et.al "Carbon/PEEK composite materials as an alternative for stainless steel/titanium hip prosthesis: a finite element study" Australas Phys Eng Sci Med DOI 10.1007/s13246-015-0380-3.

13. Gupta Krishna Rampratap et.al “An Exploration of Alternate Materials for the Design of Hip Implant” www.ijeee.in, ISSN: 2348-4748, Volume 2, Issue 7, July 2015.

14 Nikolaos I. Galaniset.al "DESIGN, NUMERICAL ANALYSIS AND MANUFACTURING OF ARTIFICIAL HIP JOINT IMPLANTS” An IACMECCOMAS Special Interest Conference-Rhodes, Greece, 22-24 June 2009.

15 M.B.N. Fanisamet.al "Finite Element Analysis of Femur Bone" International Journal of Advanced Engineering Research and Applications (IJAERA) ISSN: 2454-2377 Volume - 3, Issue - 4, August - 2017.

16 Bharathi M; Senthil Kumaran S; Edwin Samson P. "Influence of nano silica particles on quasistatic mechanical and low velocity impact properties of Carbon-glass-Sunn hemp/epoxy in intra-inter ply hybrid composites". International Research Journal on Advanced Science Hub, , , 2021, -. doi: 10.47392/irjash.2021.3753.1017

Haripriya M; G. Naga Malleswara Rao; B.Durga Prasad. "Review on Optimization of Metal Matrix Composite Connecting Rod". International Research Journal on Advanced Science Hub, 2, 7, 2020, 94-99. doi: 10.47392/irjash.2020.71 